\title{
Thrombocytopenia and Associated Factors Among HIV Infected Patients in Pre- and Post-Anti-Retroviral Therapy, North East Ethiopia
}

\author{
Feredegn Talargia $\mathbb{D}^{\prime}$ \\ Lemma Getacher $\mathbb{D D}^{2}$ \\ 'Department of Biomedical Science, \\ College of Medicine, Debre Berhan \\ University, Debre Berhan, Ethiopia; \\ ${ }^{2}$ Department of Public Health, College of \\ Health Sciences, Debre Berhan \\ University, Debre Berhan, Ethiopia
}

Background: Thrombocytopenia is a common disorder of HIV (human immunodeficiency virus) infection. The magnitude of thrombocytopenia and associated factors among HIVinfected patients receiving ART (anti-retroviral treatment) are not studied well in this study area. The aim of this study was to determine the prevalence of thrombocytopenia and associated factors in pre- and post-ART patients who attended Debre Berhan Referral Hospital (DBRH) in North-East Ethiopia.

Methods: A hospital-based cross-sectional study was conducted from October to December 2020 in DBRH, North-East Ethiopia. From the total ART patients, 272 study participants were selected randomly. Socio-demographic variables and clinical characteristics of the patients were collected by standard questionnaires. Measurement of platelet count and CD4 count were made by Sysmex XT2000i hematology machine and BD FACS count analyzer, respectively. Data were analyzed with SPSS software version 23 and multivariate logistic regression was done. $P$-value less than 0.05 was taken as statistically significant.

Results: The prevalence of thrombocytopenia was $22.7 \%$ with $95 \%$ CI: $17.8-27.5$ in preART and $14.7 \%$ with $95 \%$ CI: $11.0-19.9$ in post-ART HIV-infected patients with a significant difference at $P<0.0001$. HIV patients with CD4 counts $<200$ cells $/ \mu \mathrm{L}$ were more likely to have thrombocytopenia (35.0\%) than patients with CD4 counts $\geq 200$ with a P $<0.04$ in pre-ART patients. Patients on zidovudine (AZT)-based therapy were more likely to have thrombocytopenia (16.3\%) than patients on tenofovir (TDF)-based therapy $(14.8 \%)$ with $\mathrm{P}<0.79$; however, this did not show any significant association.

Conclusion: The prevalence of thrombocytopenia decreased significantly after the beginning of ART. HIV patients with low CD4 count and on AZT-based treatment showed high risk of thrombocytopenia. According to this study, thrombocytopenic patients were observed even after the initiation of ART. As a result, to decrease thrombocytopenic associated mortality and morbidity, there should be continuous screening for HIV-infected patients.

Keywords: ART, HIV, thrombocytopenia, Ethiopia
Correspondence: Feredegn Talargia P.O. Box: 445

Tel +251921792491

Email ftalarge@gmail.com

\section{Introduction}

HIV infection is characterized by progressive damage to the body's immune system which results in a number of opportunistic infections, and immunological and hematological complications. ${ }^{1}$ Hematological abnormalities, which can involve all lineages of blood cells and include anemia, thrombocytopenia as well as leucopenia, are the most common complications of HIV infection. ${ }^{2}$ Among these, thrombocytopenia is a frequent complication and it can occur at any stage of HIV 
infection. ${ }^{3}$ Thrombocytopenia is the second most common complication next to anemia and is found in $3-40 \%$ of individuals with HIV infection. ${ }^{4}$ The cause of thrombocytopenia has not yet been established. ${ }^{5}$ The possible mechanism may include immune-mediated platelet destruction, impaired megakaryocytes or a direct attack of megakaryocytes by HIV virus, hypersplenism, opportunistic infections, malignancy, and myelosuppression effect of medication. ${ }^{5-7}$

Thrombocytopenia has been linked to adverse sequelae and is regarded as an independent predictor of morbidity and mortality among HIV-infected group, owing to increased risk of bleeding, which may occur in mucus membranes, skin, soft tissue and intracranial sites. ${ }^{8}$ It is associated with increased morbidity and mortality, accelerated deterioration in CD4 counts and accelerated progression to full-blown acquired immunodeficiency syndrome (AIDS). ${ }^{9}$

Immune thrombocytopenic purpura (ITP) is the most common cause of thrombocytopenia in HIV-infected individuals, and often occurs at the initial stages of infection. ${ }^{10}$ The pathogenesis of ITP is still not clear, but both antibody mediated and T-cell mediated processes seem to be involved in ITP-associated platelet destruction. ${ }^{10}$ HIVassociated ITP remains an important clinical problem in the era of the widespread use of ART. Although most patients respond to primary ITP treatment and there are few treatment-related complications, nearly all patients require retreatment for recurrent ITP. ${ }^{11}$

Several studies reported that the prevalence of thrombocytopenia was higher in ART naive patients compared with patients who were on ART. ${ }^{4,8,12}$ For instance, a study conducted in Uganda showed that the prevalence of thrombocytopenia was $17.8 \%$ in ART naive patients and $13.0 \%$ in patients on ART. $^{8}$ Another study conducted in Addis Ababa, Ethiopia reported that the prevalence of thrombocytopenia was $25 \%$ in ART naïve patients and $5.7 \%$ in patients who took ART at least for six months. ${ }^{12}$

The highest prevalence of thrombocytopenia was associated with low CD4 counts, ${ }^{2,8}$ advanced stages of HIV/ AIDS, and patents on zidovudine (AZT) based therapy, ${ }^{8,12}$ but the prevalence of thrombocytopenia did not differ by sex, ethnicity or age. ${ }^{2,13}$ Many commonly used antiviral drugs affect platelet count and activation. Combined ART (cART) alone is often sufficient to correct thrombocytopenia, and the development of recurring thrombocytopenia upon cART discontinuation in some patients further strengthens the correlation. ${ }^{14}$ The ability of the nucleoside analog reverse transcriptase inhibitor (NRTI) azidothymidine (AZT, zidovudine) to affect platelet number has been extensively studied alone and in cART and AZT is reported to produce myelodysplastic syndrome with thrombocytopenia in mice. ${ }^{15}$ Although hematologic abnormalities have been widely reported in HIV-related infection, there are few data on the prevalence of thrombocytopenia and associated factors among HIV-infected patients in pre- and post-antiretroviral treatment in Ethiopia. This study provides further information on HIVassociated thrombocytopenia, and it can serve as a baseline for future studies. The aim of this study is to determine the prevalence of thrombocytopenia and associated factors in pre- and post-ART among HIV patients who attended the ART clinic at DBRH, North-East Ethiopia.

\section{Methods and Materials \\ Study Area}

This study was conducted at the ART clinic of DBRH, which is located in Debre Berhan town, North Shewa zone, Amhara region, North East Ethiopia. This institution was selected based on the availability of patients from all parts of the zone and this hospital is the only hospital serving as both a teaching and referral hospital in this zone. Beginning from September to December 2020, about 2015 patients were on ART at DBRH.

\section{Study Period}

The study was conducted from September to December 2020.

\section{Study Design}

A hospital-based cross-sectional study was conducted.

\section{Source Population}

All adult HIV-infected people who were enrolled at the ART clinic of DBRH.

\section{Study Population}

All adult HIV-infected people who fulfilled the inclusion criteria were included in this study.

\section{Inclusion and Exclusion Criteria}

Age above or equal to 18 years old, HIV-infected individuals who have been taking ART for at least six months, in DBRH were included in this study. Pregnant women, 
referred patients, patients with hematologic disorders, or severely sick patients during the data collection period were excluded from this study.

\section{Sample Size Determination}

The sample size was calculated by a single population statistical formula as follows:

$\mathrm{N}=\mathrm{z}^{2}\left(\mathrm{p}(1-\mathrm{p}) / \mathrm{d}^{2}\right.$, we consider the prevalence of thrombocytopenia $=19 \%$ from a study done previously. ${ }^{2}$ $5 \%$ level of precision(d), with $95 \%$ confidence interval and $15 \%$ non-response rate were added. Substituting the values on the above-mentioned formula, $\mathrm{n}=1.96^{2}$ $(0.19 * 0.81) / 0.05^{2} 236.48$ after the non-response rate was added, gave the final sample size of approximately 272 .

\section{Sampling Technique and Procedures}

The samples in this study were collected randomly by a lottery method until the desired sample was reached from the study population who can fulfill the inclusion criteria at the time of study period.

\section{Study Variables \\ Dependent Variable}

Prevalence of thrombocytopenia.

\section{Independent Variables}

Age, sex, clinical stages of HIV infection, CD4 count, and types of ART drugs.

\section{Data Collection and Procedures}

The standard questionnaire was prepared after observing of several literatures, and data were collected by trained ART clinic staff nurses. Socio-demographic information and clinical characteristics of the patients were collected in face to face interviews and a review of medical registration books. Blood samples were then collected by laboratory technicians and sent for hematology analysis. According to standard procedures, platelet count and CD4 cell counts were done by using Sysmex XT2000i hematology analyzer and BD FACS count system, respectively. To enhance the quality of data, the standard procedures were followed in every aspect of the procedures and quality of CD4 and hematology analyzer was checked by running the quality control along with each patient's sample. Beside that we trained the data collectors and a pre-test of the questionnaire was made plus the collected data was checked each day by the principal investigators.
Thrombocytopenia is defined as platelet counts less than 150,000 cells $/ \mu \mathrm{L}$. It was further classified as mild $(100,000-150,000$ cells $/ \mu \mathrm{L})$, moderate $(50,000-100,000$ cells $/ \mu \mathrm{L}$ ) and severe thrombocytopenia (platelet counts $<50,000$ cells $/ \mu \mathrm{L}){ }^{12}$

\section{Data Processing and Analysis}

Data were coded and entered by EPI data software version 3.1 and exported to SPSS software version 23 for analysis. The results of descriptive data were presented as frequency and percentages, whereas the continuous variables were expressed as mean \pm standard deviation. Univariate analysis was performed to determine the associations between dependent and independent variables using crude odds ratio (COR) with a $95 \%$ confidence interval (CI). Those independent variables with a $P<0.2$ in univariate analysis were included in multivariate logistic regression models. $P<0.05$ in multivariate logistic regression was considered as a statistically significant association.

\section{Result}

\section{General Characteristics of the Study Participants}

Among the 272 study participants, 110 (40.4\%) were males and $162(59.6 \%)$ were females. The mean age of the study participants was $40.494 \pm 10.88$ years. Most of the study participants were WHO stage I category in pre-ART patients.

\section{Platelet Counts and CD4 Counts of Study Participants}

The mean platelet count was $184.94 \pm 58.02 \times 10^{3} / \mu \mathrm{L}$ in preART patients and $294.32 \pm 83.7 / \mu \mathrm{L}$ in patients on ART $(\mathrm{P}<0.0001)$. The mean $\mathrm{CD} 4$ count showed an increment from $264.75 \pm 184.5$ cells $/ \mu \mathrm{L}$ in pre-ART patients to 544.0261.3cells $/ \mu \mathrm{L}$ in post-ART patients $(\mathrm{P}<0.0001)$. The most widely used ART regimen in this study was $1 \mathrm{j}$ (TDF3TC-DTG) (Table 1).

\section{Thrombocytopenia and Associated Factors in Pre-ART Patients}

The overall prevalence of thrombocytopenia in pre-ART patients was $62(22.7 \%$ with $95 \%$ CI: $17.8-27.5)$, out of this the prevalence of thrombocytopenia was $27.27 \%$ in males and $19.4 \%$ in females. From the total thrombocytopenic patients before ART, $73.8 \%, 23.0 \%$, and 3.3\% had mild, moderate, and severe thrombocytopenia cases 
Table I Socio-Demographic and Clinical Characteristics of HIVPositive Patients Taking ART at DBRH, North-East Ethiopia, 2020

\begin{tabular}{|c|c|c|}
\hline Variables & Frequency & Percentage \\
\hline \multicolumn{3}{|l|}{ Age in years } \\
\hline $18-29$ & 34 & 12.5 \\
\hline $30-39$ & 97 & 35.9 \\
\hline $40-49$ & 82 & 30.0 \\
\hline$\geq 50$ & 59 & 21.6 \\
\hline \multicolumn{3}{|l|}{ Sex } \\
\hline Male & 110 & 40.4 \\
\hline Female & 162 & 59.6 \\
\hline \multicolumn{3}{|l|}{ Marital status } \\
\hline Single & 23 & 49.8 \\
\hline Divorced & 39 & 27.5 \\
\hline Married & 135 & 8.4 \\
\hline Widowed & 75 & 14.3 \\
\hline \multicolumn{3}{|l|}{ Educational status } \\
\hline Illiterate & 74 & 27.1 \\
\hline Primary school & 92 & 33.7 \\
\hline High school & 63 & 23.1 \\
\hline Certificate and above & 44 & 16.1 \\
\hline \multicolumn{3}{|l|}{ WHO clinical stages } \\
\hline Stage I & 144 & 52.9 \\
\hline Stage II & 36 & 13.2 \\
\hline Stage III & 87 & 31.9 \\
\hline Stage IV & 5 & 1.8 \\
\hline \multicolumn{3}{|l|}{ Types of ART regimen } \\
\hline Ic & 14 & 5.1 \\
\hline Id & 10 & 3.7 \\
\hline le & 75 & 27.6 \\
\hline $\mathrm{lj}$ & 130 & 47.8 \\
\hline $2 f$ & 19 & 7.0 \\
\hline $2 \mathrm{~h}$ & 18 & 6.6 \\
\hline Not registered & 6 & 2.2 \\
\hline
\end{tabular}

Notes: Ic $=$ AZT-3TC-NVP, Id $=$ AZT-3TC-EFV, le $=$ TDF-3TC-EFV, If $=$ TDF$3 T C-N V P, \mathrm{l} j=$ TDF-3TC-DTG, $2 \mathrm{f}=$ AZT-3TC-ATV/r, $2 \mathrm{~h}=$ TDF-3TC-ATV/r.

respectively (Figure 1). In the current study the majority of thrombocytopenia cases $(28.81 \%)$ was observed in the age group $\geq 50$ years, however, the difference was not statistically significant. HIV patients who had low CD4 counts $(<200)$ were significantly associated with the highest prevalence of thrombocytopenia with a $P<0.04$ (Table 2).

\section{Thrombocytopenia and Associated} Factors in Post-ART Patients

The prevalence of thrombocytopenia was $40(14.7 \%$ with 95\% CI: 11.0-19.9) in post-ART patients. Of these patients, $80.0 \%, 17.5 \%$, and $2.5 \%$ had mild, moderate, and severe thrombocytopenia (Figure 1). The prevalence of thrombocytopenia was decreased significantly after initiation of ART by $8.0 \%(P<0.0001)$. Out of the total thrombocytopenic patients $16.51 \%$ were males and $13.58 \%$ were females. The highest prevalence of thrombocytopenia was $16.33 \%$, which was observed in the age groups between 30-39 years compared with the other age groups. The probability of having thrombocytopenia was high in patients on AZT-based therapy compared with TDF-based therapy. The prevalence of thrombocytopenia was $15.38 \%$ in patients whose CD4 counts were $<200$ cells $/ \mu \mathrm{L}$, while the prevalence of thrombocytopenia in patients whose CD4 counts were $\geq 350$ cells $/ \mu \mathrm{L}$ was $15.21 \%$ (Table 3 ).

\section{Discussion}

Hematological disorders are common among HIV-infected individuals. ${ }^{1,4,11}$ Thrombocytopenia is a common hematological syndrome of HIV/AIDS-infected patients, ${ }^{9,12}$ which is not affected by age group or gender difference. ${ }^{2}$

In the current study the prevalence of thrombocytopenia was $22.7 \%$ in pre-ART patients and $14.7 \%$ in postART patients. A similar study done in Uganda showed that the prevalence of thrombocytopenia was $17.8 \%$ in ART naive patients and $13.0 \%$ in patients on ART at least for six months. ${ }^{7}$ Another study conducted in Addis Ababa, Ethiopia reported that the prevalence of thrombocytopenia before initiation of ART was $25.0 \%$ and it was $5.7 \%$ after six months of ART . This variation may be due to differences in cut-off value platelet counts for the definition of thrombocytopenia, sample size, study design and study area.

In the current study the prevalence of thrombocytopenia in post-ART patients was decreased; this might be due to the possibility of opportunistic infections, hematologic and immune mediated related disorders being reversed in post-ART patients ${ }^{9,13}$ In this study the prevalence of thrombocytopenia did not show any statistical significant differences among age groups, or gender difference. This was in agreement with a previous study. ${ }^{1}$ 


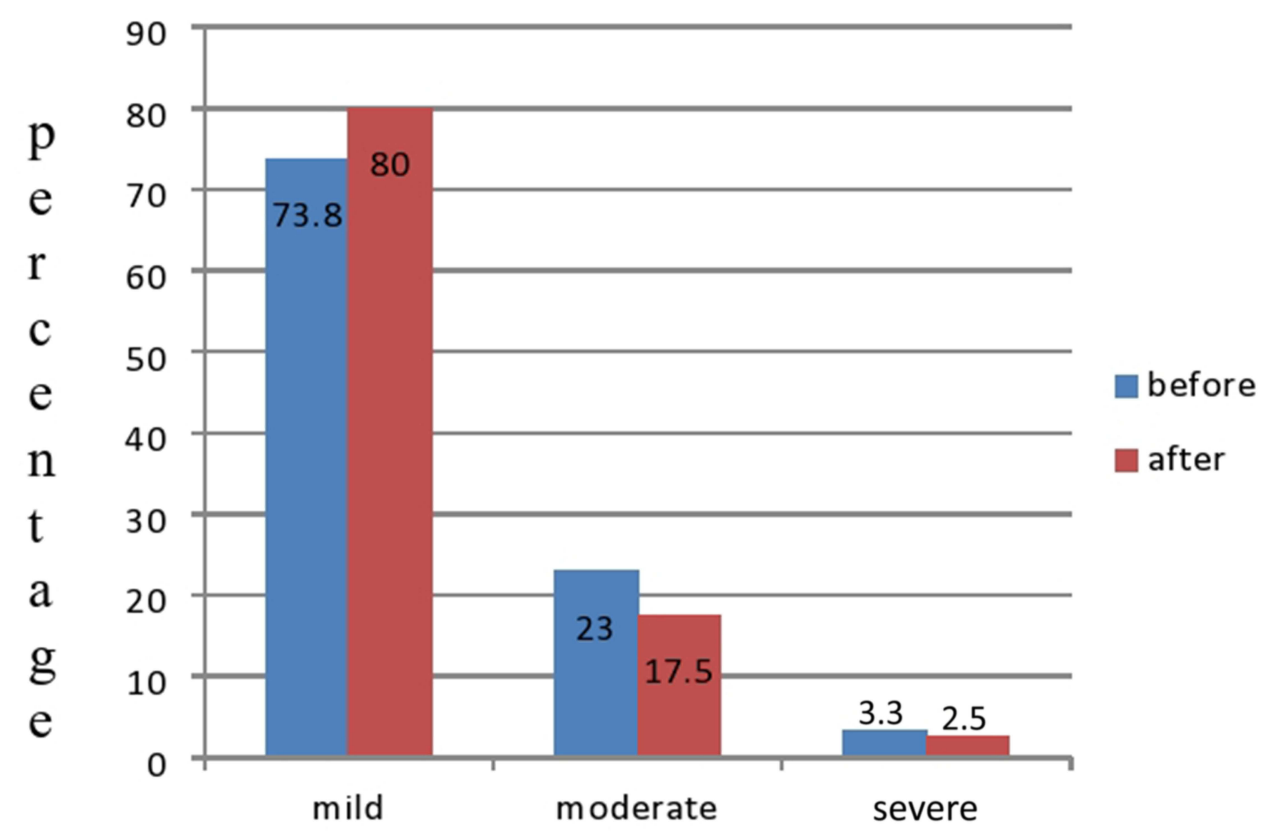

Figure I Degree of thrombocytopenia among HIV-infected patients on ART in DBRH, North-East Ethiopia.

This study showed that the prevalence of thrombocytopenia in pre-ART patients was significantly associated with low CD4 counts $(<200)$ with a $P<0.04$. Similar to this result a study conducted in China reported that thrombocytopenia was significantly associated with low CD4 counts in pre-ART patients. ${ }^{14}$ However, the prevalence of thrombocytopenia after the commencement of ART did not show a statistically significant difference after initiation of ART. This finding is supported by another study done in Gondar, Ethiopia which showed that the

Table 2 Thrombocytopenia and Associated Factors in Pre-ART HIV-Infected Patients Attending DBRH, North -East Ethiopia, 2020

\begin{tabular}{|c|c|c|c|c|c|}
\hline \multirow[t]{2}{*}{ Variables } & \multicolumn{2}{|c|}{ Thrombocytopenia } & \multirow[t]{2}{*}{ COR } & \multirow[t]{2}{*}{ AOR } & \multirow[t]{2}{*}{ P-value } \\
\hline & Yes (\%) & No (\%) & & & \\
\hline \multicolumn{6}{|l|}{ Age in groups } \\
\hline $18-29$ & $8(23.5 \%)$ & $26(76.5 \%)$ & $1.32(0.49-3.48)$ & $1.22(0.44-3.36)$ & 0.28 \\
\hline $30-39$ & $15(15.3 \%)$ & $83(84.7 \%)$ & $2.24(1.02-4.92)$ & $1.93(0.84-4.44)$ & \\
\hline $40-49$ & $22(26.8 \%)$ & $60(73.2 \%)$ & I.I (0.52-2.32) & $0.94(0.43-2.07)$ & \\
\hline$\geq 50$ & $17(28.8 \%)$ & $42(71.2 \%)$ & I & I & \\
\hline \multicolumn{6}{|l|}{ Sex } \\
\hline Male & $30(27.3 \%)$ & $80(72.7 \%)$ & $0.63(0.36-1.12)$ & $0.74(0.4-1.38)$ & 0.35 \\
\hline Female & $31(19.1 \%)$ & $|3|(80.9 \%)$ & I & I & \\
\hline \multicolumn{6}{|c|}{ WHO clinical stages } \\
\hline Stages I \& II & $34(18.8 \%)$ & $\mid 47(8 \mid .2 \%)$ & I.89(I.I-3.38) & $1.58(0.84-2.95)$ & 0.15 \\
\hline Stages III \& IV & $28(30.4 \%)$ & $64(69.6 \%)$ & I & I & \\
\hline \multicolumn{6}{|c|}{ CD4 counts (cells $/ \mu \mathrm{L}$} \\
\hline$<200$ & $4 \mathrm{I}(35.0 \%)$ & $76(65.0 \%)$ & $0.33(0.16-0.69)$ & $0.42(0.18-0.92)$ & 0.04 \\
\hline $200-349$ & $10(12.0 \%)$ & $73(88.0 \%)$ & $1.29(0.52-3.25)$ & I. $42(0.55-3.67)$ & \\
\hline$\geq 350$ & II(I5.I\%) & $62(84.9 \%)$ & & I & \\
\hline
\end{tabular}


Table 3 Thrombocytopenia and Associated Factors in HIV-Infected Patients on ART Attending DBRH, North -East Ethiopia, 2020

\begin{tabular}{|c|c|c|c|c|c|}
\hline \multirow[t]{2}{*}{ Variables } & \multicolumn{2}{|c|}{ Thrombocytopenia } & \multirow[t]{2}{*}{ COR } & \multirow[t]{2}{*}{ AOR } & \multirow[t]{2}{*}{ P-value } \\
\hline & Yes (\%) & No (\%) & & & \\
\hline \multicolumn{6}{|c|}{ Age in groups } \\
\hline $18-29$ & $4(11.8 \%)$ & $30(88.2 \%)$ & $1.35(0.38-4.77)$ & $1.35(0.38-4.79)$ & 0.86 \\
\hline $30-39$ & $16(16.3 \%)$ & $82(83.7 \%)$ & $0.92(0.38-2.25)$ & $0.87(0.36-2.13)$ & \\
\hline $40-49$ & $\mathrm{II}(\mathrm{I} 3.6 \%)$ & $70(86.4 \%)$ & $1.15(0.44-2.97)$ & $1.15(0.44-3.03)$ & \\
\hline$\geq 50$ & $9(15.3 \%)$ & $50(84.7 \%)$ & I & I & \\
\hline \multicolumn{6}{|l|}{ Sex } \\
\hline Male & $18(16.5 \%)$ & $91(83.5 \%)$ & $0.79(0.4-1.56)$ & $0.79(0.39-1.58)$ & 0.49 \\
\hline Female & $22(13.6 \%)$ & $140(86.4 \%)$ & & I & \\
\hline \multicolumn{6}{|c|}{ ART regimen } \\
\hline AZT based & $7(16.3 \%)$ & $36(83.7 \%)$ & $0.89(0.37-2.12)$ & $0.88(0.35-2.21)$ & 0.79 \\
\hline TDF based & $33(14.8 \%)$ & $190(85.2 \%)$ & I & & \\
\hline \multicolumn{6}{|c|}{ CD4 counts (cells/ $\mu \mathrm{L}$} \\
\hline$<200$ & $2(15.4 \%)$ & II (84.6\%) & $0.97(0.21-4.65)$ & $0.96(0.19-4.78)$ & 0.86 \\
\hline $200-349$ & $5(I 1.9 \%)$ & $37(88.1 \%)$ & $1.33(-0.49-3.63)$ & $1.34(0.47-3.79)$ & \\
\hline$\geq 350$ & $33(15.2 \%)$ & $184(84.8 \%)$ & I & & \\
\hline
\end{tabular}

prevalence of thrombocytopenia did not show a statistical significance with a P-value of $0.129 .{ }^{3}$ This difference in results might be due to the increment of CD4 count after the initiation of ART. ${ }^{15}$ In this study the risk of thrombocytopenia was higher in WHO clinical stages III and IV compared with WHO clinical stages I and II. This finding was in agreement with a previous study. ${ }^{7}$

The current study revealed that patients on an AZT-based ART regimen had a higher prevalence of of thrombocytopenia compared with those on a TDF-based regimen. A study conducted in Ethiopia showed the prevalence of thrombocytopenia was higher among HIV-infected patients after the initiation of ART. $^{9}$ However, there was no significant association between the presence of thrombocytopenia and types of ART-based regimen. The high prevalence of thrombocytopenia observed in zidovudine-based therapy could be due to destruction of both platelets and mega karyotypes by an immune-mediated reaction which can occurin a zidovudine containing ART-regimen. ${ }^{16}$

\section{Conclusion}

In the present study the prevalence of thrombocytopenia decreased significantly after the initiation of ART. HIV patients with low CD4 counts, advanced clinical stages and on AZT-based therapy had ahigh chance of developing thrombocytopenia. According to this study, the thrombocytopenic patients were observed even after the initiation of ART. In order to decrease thrombocytopenic associated mortality and morbidity there should be continuous screening for HIV-infected patients.

\section{Abbreviations}

AIDS, acquired immunodeficiency syndrome; ART, antiretroviral therapy; AZT, zidovudine; CD4, cluster of differentiation; HIV, human immunodeficiency virus; TDF, tenofovir; WHO, World Health Organization.

\section{Data Sharing Statement}

Data used and analyzed during the current study are available on a reasonable request from the main authors with acceptable reason.

\section{Ethical Clearance and Consent Permission}

This study was conducted after ethical letters obtained from the Institute of Research Ethics and Review Board (IRB), Institute of Medicine and Health Sciences of Debre Berhan University and complied with the Declaration of Helsinki. The institute of research and ethics board committee (IRB) had reviewed and looked at originality, feasibility; laboratory setting, and ethical aspects of the study. Following 
thorough discussion the committee approved the research proposal by authors with ethical approval using reference number med/220/2019. Then permission was taken from hospital higher management and data were collected after obtaining informed consent from the study participants. To keep confidentiality, codes were used and unauthorized persons did not have access to the data.

\section{Acknowledgments}

First of all, we would like to appreciate the staff members of ART clinic in DBRH for your incredible support in providing medical records and data collection process. Secondly, our sincere gratitude goes to Debre Berhan University for financial support to conduct this thesis.

\section{Author Contributions}

All authors had valuable contributions to the conception and design, data collection, analysis of data and interpretation; involved in drafting of the article or revising it critically for important intellectual content; agreed on journal to which the article will be submitted; gave final approval of the version to be published; agree to be accountable for all aspects of the work.

\section{Funding}

This study was funded by Debre Berhan University. The funder has no roles in the study design, data collection, and analysis, decision to publish, or preparation of the manuscript.

\section{Disclosure}

The authors report no conflicts of interest in this work.

\section{References}

1. Kumar MB, Thippeswamy T, Shankar R, Prathima C. Hematological abnormalities in early and advanced HIV infection patients. Int $J$ Sci Study. 2016;3(11):1-5.

2. Shen Y, Wang J, Wang Z, et al. A cross-sectional study of leukopenia and thrombocytopenia among Chinese adults with newly diagnosed HIV/AIDS. Biosci Trends. 2015;9(2):91-96. doi:10.5582/ bst.2015.01024

3. Tamir Z, Seid A, Haileslassie H. Magnitude and associated factors of cytopenias among antiretroviral therapy naïve human immunodeficiency virus infected adults in Dessie, Northeast Ethiopia. PLoS One. 2019;14(2):e0211708. doi:10.1371/journal.pone.0211708

4. Enawgaw B, Alem M, Addis Z, Melku M. Determination of hematological and immunological parameters among HIV positive patients taking highly active antiretroviral treatment and treatment naïve in the antiretroviral therapy clinic of Gondar University Hospital, Gondar, Northwest Ethiopia: a Comparative Cross-Sectional Study. BMC Hematol. 2014;14(1):1-7.
5. Akinbami A, Oshinaike O, Adeyemo T, et al. Hematologic abnormalities in treatment-naive HIV patients. Infect Dis. 2010;3:IDRT. S6033.

6. Gebreweld A, Fiseha T, Girma N, Haileslasie H, Gebretsadik D. Prevalence of cytopenia and its associated factors among HIV infected adults on highly active antiretroviral therapy at Mehal Meda Hospital, North Shewa Zone, Ethiopia. PLoS One. 2020;15 (9):e0239215. doi:10.1371/journal.pone.0239215

7. Khayati S, Bahri R, El Ferssani F, Yahyaoui H, Ait M, Ameur MC. Biological haematological manifestations of HIV infection. Hemoglobin. 2020;20:80.

8. Taremwa IM, Muyindike WR, Muwanguzi E, Boum Y, Boum Y II. Prevalence of HIV-related thrombocytopenia among clients at Mbarara Regional Referral Hospital, Mbarara, southwestern Uganda. J Blood Med. 2015;6:109. doi:10.2147/JBM.S80857

9. Littleton N. Thrombocytopenia in HIV. Contin Med Educ. 2007;25 (6).

10. Durandt C, Potgieter J, Mellet J, et al. HIV and haematopoiesis. $S$ Afr Med J. 2019;109(8 Supplement 1):S41-6. doi:10.7196/SAMJ.2019. v109i8b.13829

11. Ambler KLS, Vickars LM, Leger CS, et al. Clinical features, treatment, and outcome of HIV-associated immune thrombocytopenia in the HAART era. Adv Hematol. 2012;2012:910954. doi:10.1155/2012/ 910954

12. Woldeamanuel GG, Wondimu DH. Prevalence of thrombocytopenia before and after initiation of HAART among HIV infected patients at black lion specialized hospital, Addis Ababa, Ethiopia: a Cross Sectional Study. BMC Hematol. 2018;18(1):9. doi:10.1186/s12878018-0103-6

13. Wondimeneh Y, Muluye D, Ferede G. Prevalence and associated factors of thrombocytopenia among HAART naive HIV positive patients at Gondar university hospital, northwest Ethiopia. BMC Res Notes. 2014;7(1):5. doi:10.1186/1756-0500-7-5

14. Ananworanich J, Phanuphak N, Nuesch R, et al. Recurring thrombocytopenia associated with structured treatment interruption in patients with human immunodeficiency virus infection. Clin Infect Dis. 2003;37(5):723-725. doi:10.1086/376989

15. Montaner JS, Le T, Fanning M, et al. The effect of zidovudine on platelet count in HIV-infected individuals. J Acquir Immune Defic Syndr. 1990;3(6):565-570.

16. Addis Z, Yitayew G, Tachebele B. Prevalence of some hematological abnormalities among HIV positive patients on their first visit to a tertiary health institution in ethiopia; a Cross Sectional Study. Int Blood Res Rev. 2014;2(6):270-278. doi:10.9734/IBRR/2014/ 11137

17. Hekimoğlu CH, Kaptan F, Vardar I, et al. Prevalence and associated factors of thrombocytopenia among human immunodeficiency virus-infected patients at a tertiary care hospital in Izmir, Turkey. Turk J Med Sci. 2017;47(1):69-75. doi:10.3906/sag-1510-140

18. Kulkarni MB, Bhalerao MM, Mokal SJ, Krishnan B. Thrombocytopenia among HIV infected patients attending a tertiary care hospital in India. Indian J Clin Anat Physiol. 2021;7 (4):363-366. doi:10.18231/j.ijcap.2020.076

19. Fan H-W, Guo F-P, Li Y-J, Li N, Li T-S. Prevalence of thrombocytopenia among Chinese adult antiretroviral-naive HIV-positive patients. Chin Med J. 2015;128(4):459. doi:10.4103/03666999.151078

20. Fan L, Li C, Zhao H. Prevalence and risk factors of cytopenia in HIV-infected patients before and after the initiation of HAART. Biomed Res Int. 2020;2020:3132589. doi:10.1155/2020/3132589

21. Abdulqadir I, Ahmed SG, Kuliya AG, Tukur J, Yusuf AA, Musa AU. Hematological parameters of human immunodeficiency virus positive pregnant women on antiretroviral therapy in Aminu Kano Teaching Hospital Kano, North Western Nigeria. J Lab Physicians. 2018;10 (1):60-63. doi:10.4103/JLP.JLP_80_17 


\section{Publish your work in this journal}

The Journal of Blood Medicine is an international, peer-reviewed, open access, online journal publishing laboratory, experimental and clinical aspects of all aspect pertaining to blood based medicine including but not limited to: Transfusion Medicine; Blood collection, Donor issues, Transmittable diseases, and Blood banking logistics; Immunohematology; Artificial and alternative blood based therapeutics; Hematology; Biotechnology/nanotechnology of blood related medicine; Legal aspects of blood medicine; Historical perspectives. The manuscript management system is completely online and includes a very quick and fair peer-review system. Visit http://www.dovepress.com/testimonials.php to read real quotes from published authors. 